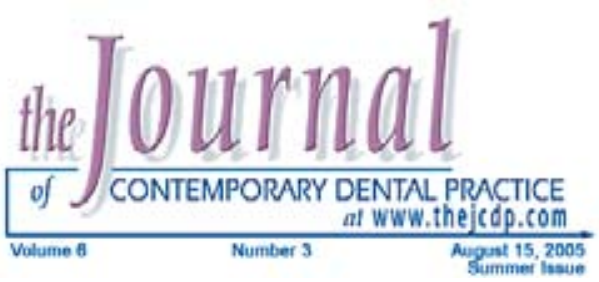

\title{
A Survey of Localized Lesions of Oral Tissues: A Clinicopathological Study
}

\author{
Anwar Bataineh, BDS, MScD, MDSc, CSOS: \\ Ziad Nawaf Al-Dwairi, BDS, PhD
}

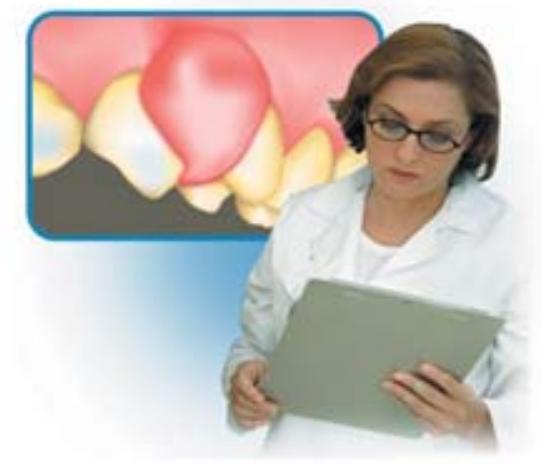

\section{Abstract}

Objective: The purpose of this study was to establish the relative prevalence of the different histopathological aspects of biopsied localized soft tissue oral lesions in a university-based dental school biopsy service.

Study Design: A retrospective analysis of patients' records with localized lesions treated in the Department of Oral Medicine and Oral Surgery between 2001 and 2004 was conducted. The lesions were classified into either fibrous lesions or soft hemorrhagic lesions. Clinical data regarding age, gender, location, and treatment of the lesions were obtained for each case.

Results: The majority of the lesions were located in the gingiva. There were a total of 294 cases of which $182(61.9 \%)$ were fibrous lesions and $112(38.1 \%)$ were soft hemorrhagic lesions. All cases were treated by excisional biopsy and elimination of the chronic irritant.

Conclusion: Although this data might be used as a guide for forming clinical impressions about oral lesions, the clinician must always be aware of the possible occurrence of more rare lesions. This study indicates there are some differences in age and gender distribution as well as in location between the different lesions.

Keywords: Localized soft tissue lesions, epulis fissuratum, fibroepithelial polyp, periphral ossifynig fibroma, neurofibroma, squamous papilloma, periphral granuloma, pregnancy tumor, peripheral giant cell granuloma

Citation: Bataineh A, Al-Dwairi ZN. A Survey of Localized Lesions of Oral Tissues: A Clinicopathological Study. J Contemp Dent Pract 2005 August;(6)3:030-039.

(C) Seer Publishing 


\section{Introduction}

The great majority of localized overgrowths of the gingiva and oral mucosa are considered to be reactive rather than neoplastic in nature. Many of these lesions can be identified as specific entities on the basis of their histopathological features and are divided into fibrous, vascular, and giant cell types. The vascular lesions present as soft, fleshy growths of a deep red color. ${ }^{1}$ The fibrous lesions of the gingiva have been widely documented and include fibrous epulis, fibroepithelial polyp, and peripheral ossifying fibroma. $^{2,3-5}$

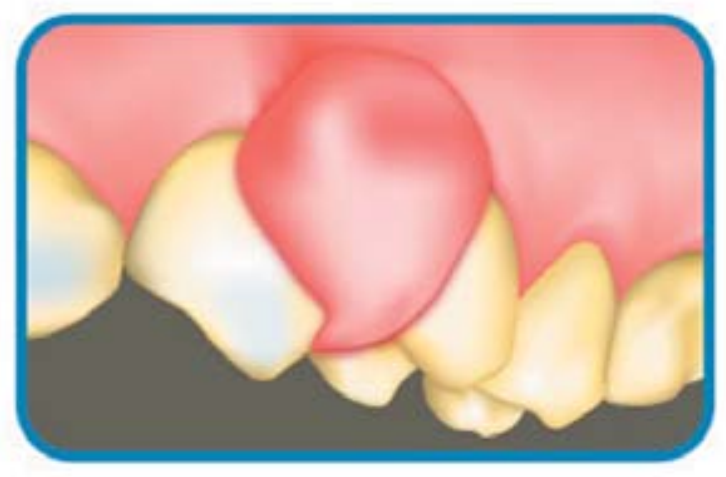

Pyogenic granuloma is a small, pedunculated, hemorrhagic nodule that occurs most frequently on the gingiva and has a strong tendency to recur following simple excision. ${ }^{6-8}$ The lesions occur in association with florid gingivitis and periodontitis that may complicate pregnancy and are referred to as pregnancy epulis or tumor. ${ }^{9}$ The soft hemorrhagic lesions are highly vascular; hemorrhage is a prominent clinical and histological feature. Fibrous inflammatory hyperplasias may occur on any surface of the oral mucous membrane as either pedunculated or sessile growth. On the gingiva, a similar lesion is often referred to as an epulis, that is, a growth on the gum. The majority remain small, and lesions more than $1 \mathrm{~cm}$ in diameter are rare on the cheeks, tongue, and floor of the mouth possibly because masticatory trauma restricts their size through necrosis and ulceration. ${ }^{10}$ An exception to this rule occurs in lesions associated with the periphery of ill-fitting dentures, the socalled epulis fissuratum, in which the growth is often divided by the edge of the denture. ${ }^{11}$ On the dorsal surface of the tongue, nodular lesions may represent neurofibroma as well as fibrous inflammatory hyperplasia.
Fibrous inflammatory hyperplasias have no malignant potential, and recurrences following excision are almost always a result of failure to eliminate the particular chronic irritation involved. Therefore, fibrous inflammatory hyperplasias of the oral cavity should be treated by complete local excision and removal of the chronic irritant.

Dental professionals often detect these lesions. Knowledge of the frequency and presentation of the most common lesions is beneficial in developing a clinical impression of such lesions encountered in practice.

The purpose of this study was to establish the relative prevalence of the different biopsied localized oral fibrous lesions. These lesions include: epulis fissuratum, fibroepithelial polyp, periphral ossifynig fibroma, and neurofibroma, in addition to squamous papilloma as an epithelial proliferation and of soft hemorrhagic lesions. Hemorrhagic lesions included: periphral granuloma, pregnancy tumor, and peripheral giant cell granuloma in a university-based faculty of dentistry biopsy service.

\section{Materials and Methods}

The histopathological diagnosis of the gingival and oral tissue lesions treated in the Department of Oral Medicine and Oral Surgery, Faculty of Dentistry, Jordan University of Science and Technology, between January 2001 and May 2004 were reviewed. The lesions were classified into two groups: fibrous lesions predominantly comprised of collagenous connective tissue (epulis fissuratum, fibroepithelial polyp, peripheral ossifying fibroma, neurofibroma) and soft hemorrhagic lesions (pyogenic granuloma, pregnancy tumor, and peripheral giant-cell granuloma).

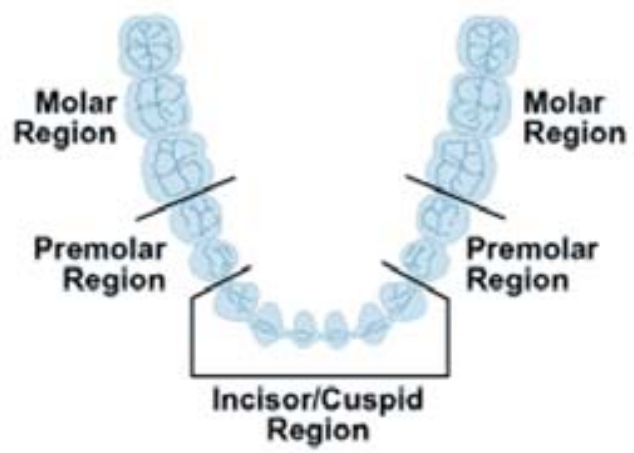


Clinical data regarding age, gender, location of the lesion, and treatment were obtained for each case from patients' records. For the purpose of recording the location of lesions, each jaw was divided into an incisor/cuspid region, a premolar region, and a molar region. The incisor/cuspid region extended from the mesial surface of the one canine to the mesial surface of the other canine and the premolar region from the distal surface of the canine to the mesial surface of the first permanent molar. Deciduous molars were included in the premolar region. The molar region extended from the mesial surface of the first molar to the anterior border of the ramus. The other locations were upper and lower lips, hard and soft palate, tongue, and buccal mucosa. All the lesions were treated by excisional biopsy and elimination of the chronic irritant at the time the lesion was excised.

The total number of localized gingival and oral tissue lesions was detemined both as an absolute number and as a percentage of the total number of the lesions.

\section{Results}

The histological features and clinical relevance of the lesions were examined and analyzed. A total of 294 surgical specimens of lesions of the oral cavity presented clinically were studied; 182 (61.9\%) were fibrous lesions and 112 (38.1\%) were soft hemorrhagic lesions. The fibrous lesions included $54(29.7 \%)$ gingival lesions; $128(70.3 \%)$ were located in different areas in the oral cavity. Whereas $94(83.9 \%)$ of the soft hemorrhagic lesions were gingival lesions and 18 $(16.1 \%)$ were in other locations of the oral cavity tissues. The patients were treated by excisional biopsy and elimination of the chronic irritant simultaneously.

\section{Age}

The age of the patient at the time of excision ranged from 5 to 90 years. The distribution of different types of fibrous lesions in relation to age is shown in Table 1. The most common lesion was the fibroepithelial polyp and the peak was in the 31 to 40 year old age group $(31 ; 10.54 \%)$, followed by the 51 to 60 year old age group in 23 $(7.82 \%)$ cases.

Table 1. Distribution of fibrous lesions by age.

\begin{tabular}{|c|c|c|c|c|c|c|}
\hline & \multicolumn{5}{|c|}{ Fibrous Lesions } & \multirow[b]{2}{*}{ Total Nb- } \\
\hline $\begin{array}{c}\text { Age } \\
\text { (rears) }\end{array}$ & $\begin{array}{c}\text { Epuifs } \\
\text { Fissumatum } \\
\text { Na(\%) }\end{array}$ & $\begin{array}{c}\text { Squamous } \\
\text { Papillama } \\
\text { Na (X) }\end{array}$ & $\begin{array}{l}\text { Fitroepithelfl' } \\
\text { Podyp Na (X) }\end{array}$ & $\begin{array}{l}\text { Peripheral } \\
\text { Fibroma Na (X) }\end{array}$ & $\begin{array}{c}\text { Nauiofibroma } \\
\text { Na ( } \%)\end{array}$ & \\
\hline $0-10$ & 6 & $2(0.68)$ & $7(2.38)$ & $4(1.36)$ & 0 & $13(4.42)$ \\
\hline $11-20$ & to & to & $9(3.06)$ & $6(2.04)$ & to & $15(5.1)$ \\
\hline $21-30$ & to & $3(1.02)$ & $20(6.8)$ & $3(2.72)$ & $2(0.68)$ & $33(11.22)$ \\
\hline $31-40$ & 0 & to & $31(10.54)$ & $6(2.04)$ & 0 & $37(12.59)$ \\
\hline $41-50$ & $3(1.02)$ & to & $14(4.76)$ & $10(3.4)$ & 10 & $27(9.18)$ \\
\hline $51-60$ & $10(3.4)$ & 10 & $23(7.82)$ & $2(0.68)$ & 10 & $35(11.9)$ \\
\hline $61-70$ & $5(1.7)$ & 10 & $14(4.76)$ & to & 10 & $19(6.46)$ \\
\hline$>70$ & 0 & b & $3(1.02)$ & 0 & 0 & $3(1.02)$ \\
\hline Total & $18(6.12)$ & $5(1.7)$ & $121(41.16)$ & $36(12.24)$ & $2(0.68)$ & $182(61.9)$ \\
\hline
\end{tabular}

Table 2. Distribution of soft hemorrhagic lesions by age.

\begin{tabular}{|c|c|c|c|c|}
\hline & \multicolumn{3}{|c|}{ Soft Hemonhagic Lesions } & \\
\hline $\begin{array}{c}\text { Age } \\
\text { (Years) }\end{array}$ & $\begin{array}{c}\text { Pyogenic } \\
\text { Ganulama Na } \%\end{array}$ & $\begin{array}{l}\text { Pregnancy } \\
\text { Tumor } \mathrm{Na} \text { (\%) }\end{array}$ & $\begin{array}{l}\text { Peripheral Giant Col } \\
\text { Geanuloma Na(*) }\end{array}$ & Total Nb_(\%) \\
\hline $0-10$ & $9(3.06)$ & 0 & $14(4.76)$ & $23(7.82)$ \\
\hline $11-20$ & $25(8.5)$ & to & $6(2.04)$ & $31(10.54)$ \\
\hline $21-30$ & $12(4.08)$ & $6(2.04)$ & $4(1.36)$ & $22(7.48)$ \\
\hline $31-40$ & $9(3.06)$ & 0 & $11(3.74)$ & $20(6.8)$ \\
\hline $41-50$ & $6(2.04)$ & 0 & 0 & $6(2.04)$ \\
\hline $51-60$ & to & 0 & 10 & to \\
\hline $61-70$ & $2(0.68)$ & to & $3(1.02)$ & $5(1.7)$ \\
\hline$>70$ & $5(1.7)$ & to & 0 & $5(1.7)$ \\
\hline Total & $68(23.13)$ & $6(2.04)$ & $38(12.93)$ & $112(38.1)$ \\
\hline
\end{tabular}


The distribution of soft hemorrhagic lesions in relation to age is shown in Table 2. Pyogenic granuloma was the most common lesion in $25(8.5 \%)$ in the 11 to 20 year old age group, followed by peripheral giant cell granuloma in $14(4.76 \%)$ cases in the 0 to 10 year old age group. All age groups were found to be affected with a relative predilection from 11 to 40 years of age. The fibrous lesions tended to occur in the adult age group. The largest number 96 $(32.64 \%)$ of cases were from individuals between 21 to 60 years of age, while the largest number $132(44.89 \%)$ of soft hemorrhagic lesions were from individuals between 0 to 40 years of age.

\section{Gender}

Of the biopsied lesions, $182(61.9 \%)$ were from female patients and $112(30.1 \%)$ were from male patients. The distribution of fibrous lesions in relation to gender is shown in Table 3; the most common lesion was the fibroepithelial polyp found in 121 (41.16\%) cases. The distribution of soft hemorrhagic lesions in relation to gender is shown in Table 4; the most common lesion of the soft hemorrhagic lesions was pyogenic granuloma found in $68(23.13 \%)$ cases.

\section{Location}

Of the 294 biopsies, 148 (50.34\%) were from the gingiva of either the upper or lower jaw and $146(49.66 \%)$ were from other sites of the oral cavity. The fibroepithelial polyp was the most common lesion found, which was diagnosed in $121(41.16 \%)$ of the lesions. The pyogenic granuloma was diagnosed in $52(17.69 \%)$ of the gingival lesions.

The distribution of the fibrous lesions according to location is shown in Table 5 . The most common location of fibrous lesions was in buccal mucosa.

The fibrous lesions and their distribution included $49(16.67 \%)$ cases of fibroepithelial polyp, followed by $32(10.88 \%)$ tongue cases, $6(2.04 \%)$ cases each in the upper and lower lip. There were also $4(1.36 \%)$ cases each in the hard and soft palates.

The distribution of soft hemorrhagic lesions according to location is shown in Table 6. The most common location of the $52(17.69 \%)$ soft hemorrhagic lesions was pyogenic granuloma found on the gingiva of both jaws.

Table 3. Distribution of fibrous lesions by gender.

\begin{tabular}{|c|c|c|c|c|c|c|}
\hline \multirow[b]{2}{*}{ Cender } & \multicolumn{5}{|c|}{ Fibrousc Lesions } & \multirow[b]{2}{*}{ Tota Nb_(\%) } \\
\hline & $\begin{array}{c}\text { Epuls } \\
\text { Fissuratum } \\
\text { Na (\%) }\end{array}$ & $\begin{array}{l}\text { Squamous } \\
\text { Papilloma } \\
\text { Na (\%) }\end{array}$ & $\begin{array}{l}\text { Fibroepithefia } \\
\text { Polyp Na (\%) }\end{array}$ & $\begin{array}{l}\text { Periphera: } \\
\text { Fitroma/2 }\end{array}$ & $\begin{array}{c}\text { Naurof ibroms } \\
\text { Na (\%) }\end{array}$ & \\
\hline Male & $8(2.72)$ & $3(1.02)$ & $43(14.63)$ & $18(6.12)$ & $2(0.68)$ & $74(25.17)$ \\
\hline Female & $10(3.4)$ & $2(0.68)$ & $78(26.53)$ & $18(6.12)$ & 0 & $108(36.73)$ \\
\hline Total & $18(6.12)$ & $5(1.7)$ & $121(41.16)$ & $36(12.24)$ & $2(0.68)$ & $182(61.9)$ \\
\hline
\end{tabular}

Table 4. Distribution of soft hemorrhagic lesions by gender.

\begin{tabular}{|c|c|c|c|c|}
\hline & \multicolumn{3}{|c|}{ Soft Hemonhagic Lesions } & \\
\hline Gender & $\begin{array}{c}\text { Pyogenic } \\
\text { Ganuloma Na(\%) }\end{array}$ & $\begin{array}{c}\text { Pregnancy Tumoi } \\
\text { Na(\%) }\end{array}$ & $\begin{array}{c}\text { Peripheral Giant CeI } \\
\text { Ganulama Na(\%) }\end{array}$ & Total No.(\%) \\
\hline Male & $24(8.16)$ & 0 & $14(4.76)$ & $38(12.93)$ \\
\hline Female & $44(14.97)$ & $6(2.04)$ & $24(8.16)$ & $74(25.17)$ \\
\hline Total & $68(23.13)$ & $6(2.04)$ & $38(12.93)$ & $112(38.1)$ \\
\hline
\end{tabular}




\begin{tabular}{|c|c|c|c|c|c|c|c|}
\hline 현 & $\frac{\widehat{s}}{\dot{c}}$ & $\stackrel{\frac{\widehat{y}}{\varphi}}{\stackrel{\varphi}{\varphi}}$ & $\stackrel{\hat{F}}{=}$ & $\stackrel{\widehat{0}}{\frac{0}{\sigma}}$ & 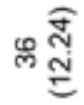 & N & $\stackrel{\infty}{\stackrel{\sigma}{-}}$ \\
\hline \multirow{6}{*}{ 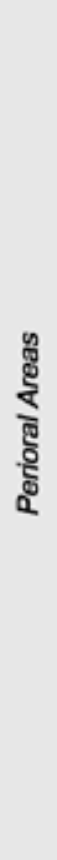 } & 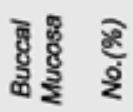 & 0 & 0 & 奇 & 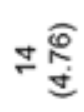 & 0 & ஜ \\
\hline & 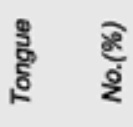 & 0 & 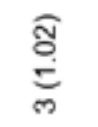 & బ & 0 & 0 & 品 \\
\hline & ஸั: & 0 & N & 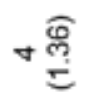 & 0 & 0 & $\bullet$ ठ্] \\
\hline & 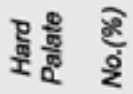 & 0 & 0 & $\forall \stackrel{\widehat{\mathscr{Q}}}{=}$ & $\omega \stackrel{\widehat{d}}{\mathrm{~d}}$ & 0 & 앙 \\
\hline & 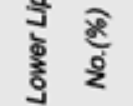 & 0 & 0 & ○ 엉 & N & 0 & $\infty \stackrel{\text { d }}{\text { d. }}$ \\
\hline & 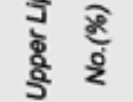 & 0 & 0 & ○ & 0 & 0 & $\bullet \stackrel{\widehat{d}}{\mathrm{~d}}$ \\
\hline \multirow{3}{*}{ 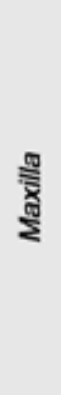 } & 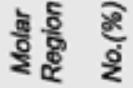 & N & 0 & N & $\omega \stackrel{\widehat{్}}{\mathrm{~S}}$ & 0 & 앙 \\
\hline & 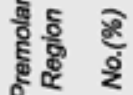 & N & 0 & 0 & 0 & N & $\nabla \stackrel{\mathscr{D}}{=}$ \\
\hline & 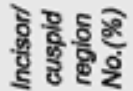 & $\bullet \stackrel{\text { d }}{\mathrm{d}}$ & 0 & $\infty \underset{\mathrm{N}}{\mathbb{N}}$ & N & 0 & $\stackrel{\widehat{\sigma}}{\vec{f}}$ \\
\hline \multirow{3}{*}{$\begin{array}{l}\text { हैं } \\
\text { है }\end{array}$} & 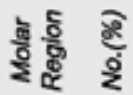 & 0 & 0 & 0 & N & 0 & N \\
\hline & 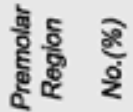 & N & 0 & $\omega \stackrel{\widehat{d}}{\mathrm{~d}}$ & N & 0 & 유욤 \\
\hline & 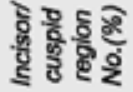 & ๑ & 0 & 呛 & N $\stackrel{\widehat{\mathscr{g}}}{\stackrel{\leftrightarrow}{\varrho}}$ & 0 & 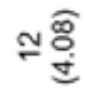 \\
\hline 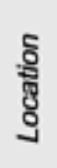 & 娄 & 垴 & 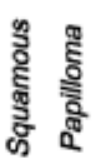 & 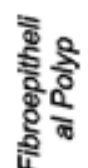 & 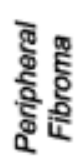 & 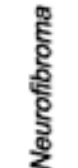 & ஓ \\
\hline
\end{tabular}




\begin{tabular}{|c|c|c|c|c|c|}
\hline 욤 & ஓ্ & 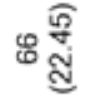 & ० $\underset{\mathbb{d}}{\widehat{O}}$ & 足 & 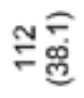 \\
\hline \multirow{6}{*}{ 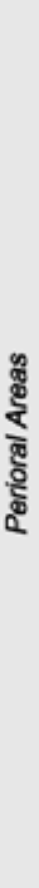 } & 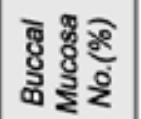 & N & 0 & N & + \\
\hline & ฏัฐ & 0 & 0 & 0 & 0 \\
\hline & ธัฐ & 0 & 0 & 0 & 0 \\
\hline & 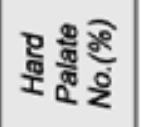 & 0 & 0 & 0 & 0 \\
\hline & 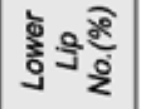 & $\infty \stackrel{\text { ล }}{\mathrm{d}}$ & 0 & 0 & $\infty \underset{\mathbb{N}}{\mathbb{N}}$ \\
\hline & 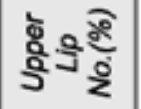 & $\omega \widehat{\overparen{J}}$ & 0 & 0 & $\omega \underset{\mathrm{d}}{\widehat{\mathbb{J}}}$ \\
\hline \multirow{3}{*}{ 竞 } & 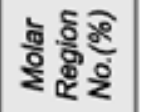 & $\infty \underset{\mathbb{N}}{\widehat{N}}$ & 0 & N & 울 \\
\hline & 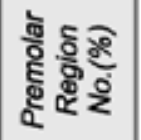 & $\pm \frac{\widehat{Q}}{\dot{E}}$ & 0 & 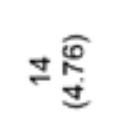 & 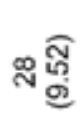 \\
\hline & 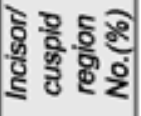 & 앙 & 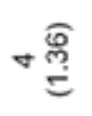 & 0 & 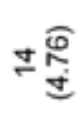 \\
\hline \multirow{3}{*}{ : } & 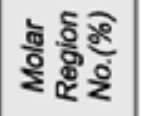 & 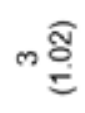 & 0 & $\nabla \stackrel{\widehat{p}}{=}$ & ^ \\
\hline & 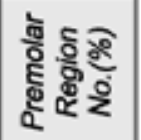 & 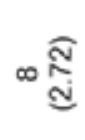 & N & 0 & 앙 \\
\hline & 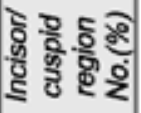 & $\infty \stackrel{0}{c}$ & 0 & 웜 & బ \\
\hline ई్ㅀㅀ & 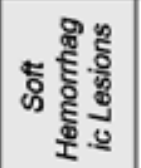 & 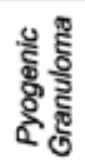 & 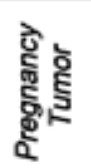 & 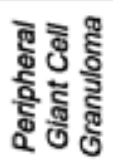 & ๕ \\
\hline
\end{tabular}




\section{Discussion}

Comparison of the findings of the present study with other similar epidemiological studies is difficult because a limited number of studies report the prevalence of such oral mucosal lesions worldwide. This study is the first report on the relative prevalence and distribution of intraoral localized lesions, classified into fibrous lesions and soft hemorrhagic lesions.

The result of this study shows fibroepithelial polyp was the most common of the fibrous lesions, and of the soft hemorrhagic lesions pyogenic granuloma was the most common. Some differences in age, gender distribution, and location were found between the different histological groups. Pyogenic granuloma was the most common lesion on the gingiva in different studies. ${ }^{12,13}$ Pyogenic granuloma occurs in younger patients more often than fibrous hyperplasia and, thus, may represent a stage in the development of fibrous hyperplasia. ${ }^{13}$

Fibrous lesions occur in older age groups as compared to soft hemorrhagic lesions. Cooke ${ }^{14}$ observed the greatest number of cases of fibrous hyperplasia was in the fourth decade, while Buchner et al. ${ }^{12}$ found the majority of the cases occurred in the third, fourth, and fifth decade, and Kfir et al. ${ }^{13}$ found the majority of cases mainly in the second, third, and fourth decade. In this study the most frequently affected age was between 21 and 60 years old, which is in agreement with other reported studies. ${ }^{12,13}$ This benign lesion has no age or gender predilection although some previous studies reported a slightly higher incidence in females. ${ }^{5,15-18}$ In this study it was found females were more commonly affected than males. The results obtained in this study were overall in agreement with other studies. ${ }^{5,15}$ Females are more frequently affected with pyogenic granuloma, which was the most common localized hyperplastic overgrowth on the gingiva. ${ }^{12,13}$ In a study of 302 consecutive localized gingival outgrowths it was found pyogenic granuloma occured in all ages but mainly in youngsters. ${ }^{12}$ In our study pyogenic granuloma was the most common lesion, similar to that reported by Buchner et al. ${ }^{12}$ and Kfir et al. ${ }^{13}$ who grouped pregnancy epulis with pyogenic granuloma in their study. In the present study the pregnancy epulis and pyogenic granuloma were separated into two different entities. There was no marked difference between the involvement of the mandible and the maxilla. ${ }^{12,13}$

Peripheral giant cell granuloma shows a wide age distribution. Giansanti and Waldron ${ }^{3}$ reported it occurred at the mean age of 31.3 years. In our series the peripheral giant cell granuloma was distributed in all ages without any clear preference, and the mean age was 41 years old. This mean age is relatively high as compared to what appears in the literature ${ }^{3}$ and in agreement with that reported by Buchner et al. ${ }^{12}$ Peripheral giant cell granuloma appears to be more common in the mandible than in the maxilla, which is in agreement with what has been reported in previous studies. ${ }^{12,14}$

The majority of inflammatory reactive hyperplasias occurred on the surface of the oral mucous membrane where irritants are quite common. The majority of inflammatory reactive hyperplasias will not recur, thereby, confirming the benign nature of these lesions as would be expected from their histological structure.

Epulis is a clinical term used to describe a localized growth on the gingiva. Histological examination of epulides indicates the vast majority are focal fibrous hyperplasias, peripheral ossyfing fibromas, pyogenic granulomas, or peripheral giant cell granulomas. ${ }^{10}$ There is some disagreement about the validity of the clinical term "pregnancy tumor." On the basis of its clinical presentation and histological appearance, some authors believe it simply represents a pyogenic granuloma, whereas others believe the lesion is unique because of the apparent influence of female sex hormones. ${ }^{9}$

In the present study epulis fissuratum occurred mainly in the fourth, fifth, and sixth decade. Thus, these findings are in general agreement with Buchner et al. ${ }^{12}$ Males and females as well 
as the maxilla and mandible were almost equally affected, which is different from other studies. $^{12,19,20}$ The higher prevalence in females, as has been reported in other studies, may be due to hormonal alterations during menopause. ${ }^{12}$

\section{Conclusion}

Although these data might be used as a guide for forming clinical impressions about oral lesions, the clinician must always be aware of the possible occurrence of more rare lesions. This study indicates there are some differences in age and gender distribution as well as in location between the different lesions.

\section{References}

1. MacLeod RI, Soames JV. Epulides: a clinicopathological study of a series of 200 consecutive lesions. Br Dent J 1987;163:51.

2. Buchner A, Hansen LS. The histomorphologic spectrum of peripheral ossifying fibroma. Oral Surg Oral Med Oral Pathol 1987;63:452-61.

3. Giansanti JS, Waldron CA. Peripheral giant cell granuloma: review of 720 cases. J Oral Surg. 1969 Oct;27:787-91.

4. Wood NK, Goaz PW. Differential diagnosis of oral lesions. 4th ed. St. Louis: Mosby-Year Book, 1991:393-5.

5. Lee KW. The fibrous epulis and related lesions. Granuloma pyogenicum, 'Pregnancy tumour', fibroepithelial polyp and calcifying fibroblastic granuloma. A clinico-pathological study. Periodontics. 1968;6:277-92.

6. Angelopoulos AP. Pyogenic granuloma of the oral cavity: statistical analysis of its clinical features. J Oral Surg. 1971;29:840-7.

7. Poonja LS, Bhatt AP. Case of the month. Pyogenic granuloma. J Indian Dent Assoc. 1983;55:

8. Vilmann A, Vilmann $\mathrm{P}$, Vilmann $\mathrm{H}$. Pyogenic granuloma: evaluation of oral conditions. $\mathrm{Br} \mathrm{J}$ Oral Maxillofac Surg. 1986;24:376-82.

9. Daley Td, Nartley Ni, Wysocki GP. Pregnancy tumor: An analysis. Oral Surg Oral Med Oral Pathol 1991; 72:196.

10. Daley TD, Wysocki GP, Wysocki PD, et al. The major epulides: a clinicopathological correlations. J Can Dent Assoc 1990;56:627.

11. Budtz-Jorgensen E. Oral mucosal lesions associated with the wearing of removal dentures. J Oral Pathol 1981;10:65.

12. Buchner A, Calderon S, Ramon Y. Localized hyperplastic lesions of the gingiva: a clinicopathological study of 302 lesions. J Periodontol. 1977;48:101-4.

13. Kfir Y, Buchner A, Hansen LS. Reactive lesions of the gingiva. A clinicopathological study of 741 cases. J Periodontol. 1980;51:655-61.

14. Cooke BED. The fibrous epulis and the fibroepithelial polyp: their histogenesis and natural history. Brit D J 1952;93:305-9

15. Kerr DA. Granuloma pyogenicum. Oral Surg Oral Med Oral Pathol. 1951;4:158-76.

16. Regezi JA, Sciubba JJ. Oral pathology: clinical-pathologic correlations. 2nd ed. Philadelphia: WB Saunders, 1989:379-81.

17. Zain RB, Fei YJ. Fibrous lesions of the gingiva: a histopathologic analysis of 204 cases. Oral Surg Oral Med Oral Pathol. 1990;70:466-70.

18. Inagi K, Takahashi HO, Yao K, et al. Study of pyogenic granuloma of the oral cavity. Nippon Jibiinkoka Gakkai Kaiho. 1991;94:1857-64.

19. Nordenram A, Landt H. Hyperplasia of the oral tissues in denture cases. Acta Odontol Scand. 1969;27:481-91.

20. Cutright DE. The histopathologic findings in 583 cases of epulis fissuratum. Oral Surg Oral Med Oral Pathol. 1974;37:401-11. 


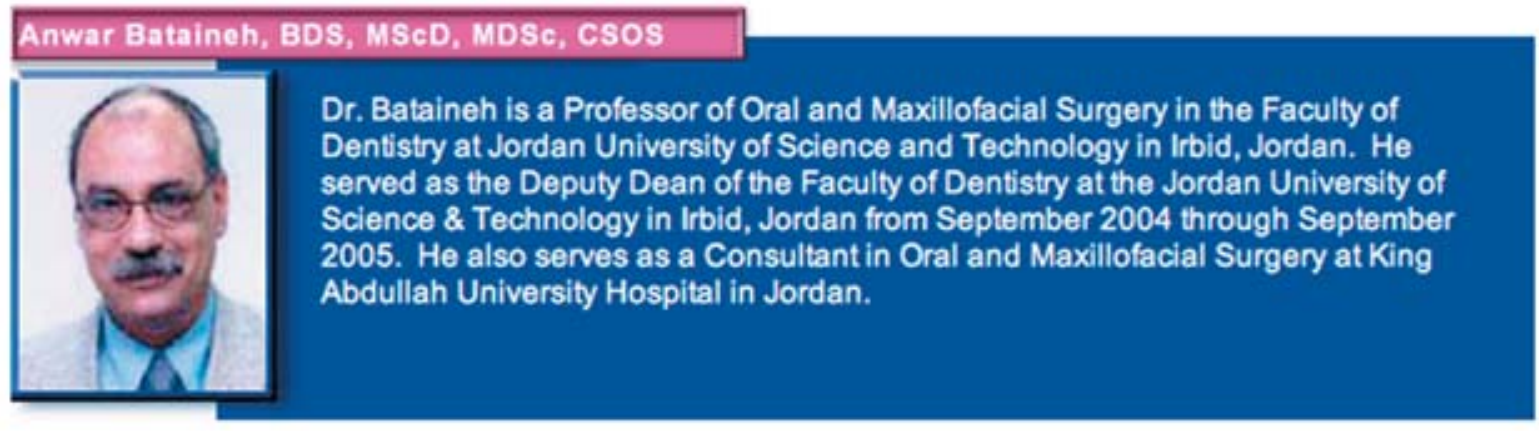

\section{Zlad Nawaf Al-Dwairi, BDS, PhD}

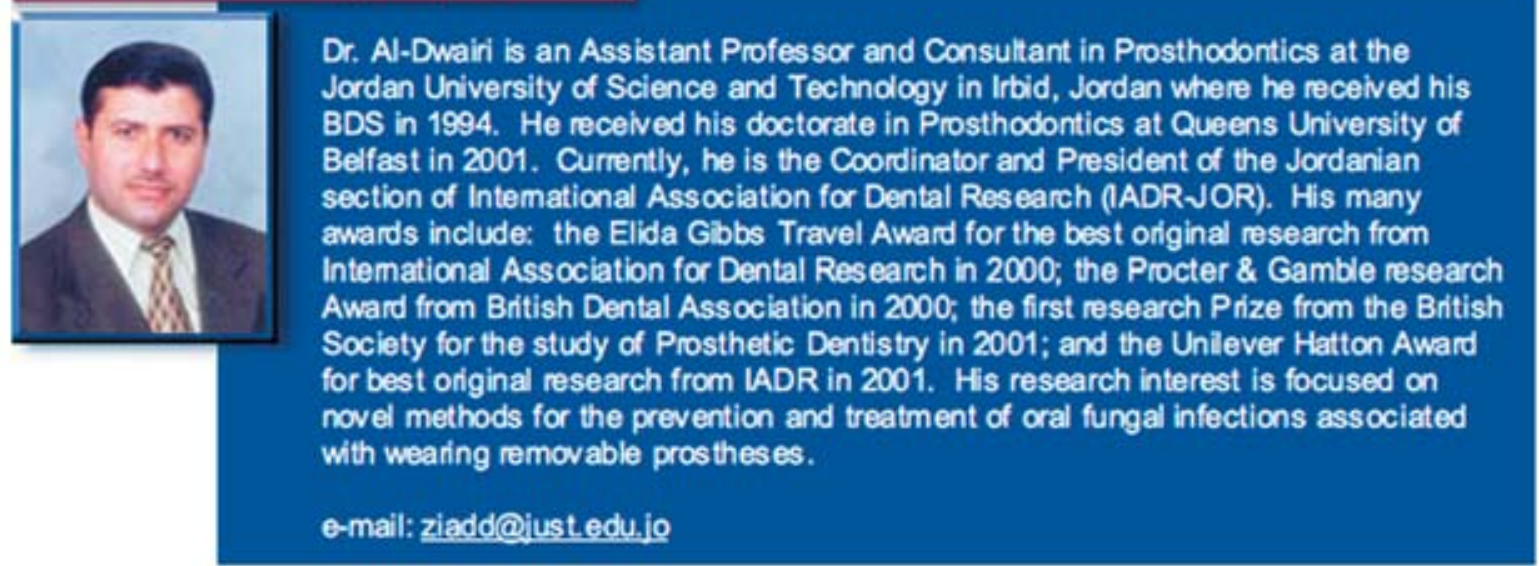

